in vivo $34: 2745-2750(2020)$

doi:10.21873/invivo.12097

\title{
Impact of Acridine Orange in Patients With Local Recurrent Soft Tissue Sarcoma
}

\author{
HIROYUKI TSUCHIE ${ }^{1}$, MAKOTO EMORI ${ }^{2}$, NAOHISA MIYAKOSHI ${ }^{1}$, KYOJI OKADA $^{3}$, \\ HIROYUKI NAGASAWA ${ }^{1}$, YASUTAKA MURAHASHI ${ }^{2}$, EMI MIZUSHIMA ${ }^{2}$, \\ JUNYA SHIMIZU $^{2}$, TOSHIHIKO YAMASHITA ${ }^{2}$ and YOICHI SHIMADA ${ }^{1}$
}

\author{
${ }^{1}$ Department of Orthopedic Surgery, Akita University Graduate School of Medicine, Akita, Japan; \\ ${ }^{2}$ Department of Orthopedic Surgery, Sapporo Medical University School of Medicine, Sapporo, Japan; \\ ${ }^{3}$ Department of Physical Therapy, Akita University Graduate School of Health Sciences, Akita, Japan
}

\begin{abstract}
Background/Aim: Local recurrence in soft tissue sarcoma (STS) is a risk factor of worse prognosis. Although a few studies have shown that adjuvant therapy with acridine orange (AO) is effective for local control of primary STS, there have been no reports examining its effectiveness for local recurrence. Patients and Methods: This retrospective study included 36 patients with first local recurrence of STS. Of them, 23 patients received wide excision without AO therapy (Wide group); the other 13 patients received marginal excision with AO therapy (AO group). We compared re-recurrence rates between these two groups. Results: The total re-recurrence rate was $43.5 \%$ in the Wide group and $46.2 \%$ in the AO group. There was no significant difference in local re-recurrence-free survival and overall survival between the two groups. Conclusion: Adjuvant AO therapy combined with a marginal excision suppresses local re-recurrence rates of individuals with local STS recurrence.
\end{abstract}

Soft tissue sarcoma (STS) is relatively rare compared with other types of cancer. Radical resection with an adequate margin is important in the treatment of STS for the prevention of local recurrence. However, when tumors are in contact with important tissues such as major nerves or blood vessels, removing these important tissues can cause serious dysfunction. If resection is conducted in the area where the tumor is in contact with the tissue, the recurrence rate increases. Local recurrence itself is a risk factor of local re-

This article is freely accessible online.

Correspondence to: Hiroyuki Tsuchie, MD, (ORCID: 0000-0001-50117184), Department of Orthopedic Surgery, Akita University Graduate School of Medicine, 1-1-1 Hondo, Akita 010-8543, Japan. Tel: +81 188846148, Fax: +81 188362617, e-mail: tuchikiti@yahoo.co.jp

Key Words: Acridine orange, local recurrence, soft tissue sarcoma. recurrence and a worse prognosis; once local recurrence occurs, it is more difficult to control the STS (1).

Kusuzaki et al. were the first to report the effectiveness of acridine orange (AO) treatment as an adjuvant therapy in soft tissue sarcomas in various different studies (2-8). AO accumulates in acidic environments. As sarcoma cells have many large acidic vesicles, AO specifically binds to malignant tumors and immediately accumulates in tumor cells after local administration (9-13). AO has a strong celldestructive effect on tumor cells after a single session of blue light excitation or low-dose radiation, which kills residual tumor cells after tumor resection.

Several studies have shown that adjuvant therapy with AO is effective on the local control of primary STS $(2-8,14)$. However, there have been no reports examining the effectiveness of AO treatment for local recurrence cases of STS. The aim of this study was to clarify the efficacy of AO therapy by comparing marginal excisions with adjuvant $\mathrm{AO}$ therapy and wide excisions in STS patients with local recurrence.

\section{Patients and Methods}

Patients. Forty-two STS patients with local recurrence involving the extremities or trunk were treated with surgical resection, with the exception of amputation surgery, conducted in the Akita University Hospital and Sapporo Medical University Hospital between January 1994 and December 2019. They had not developed distant metastases prior to the surgery for the local recurrence. We defined marginal excision as a resection through the capsule of the tumor and intralesional excision as resection through the tumor; we excluded 4 cases of marginal excision without AO therapy and 2 cases of intralesional excision in this study. Consequently, 36 patients with local STS recurrence treated with wide excision or marginal excision with AO therapy, with a mean age of 66.9 years (range $=32-88$ years), were included in this study. Twenty-three of the 36 patients underwent wide excision on the recurrent lesion (Wide group), and the other 13 patients were treated by marginal excision with AO therapy on the recurrent lesions (AO group). 
Table I. Comparison of patient characteristics between those in the wide excision and those in the acridine orange groups.

\begin{tabular}{|c|c|c|c|}
\hline & $\begin{array}{l}\text { Wide group } \\
\qquad \%)\end{array}$ & $\begin{array}{l}\mathrm{AO} \text { group } \\
\quad(\%)\end{array}$ & $p$-Value \\
\hline Number & 23 & 13 & \\
\hline Age (years) & $68.4 \pm 17.9$ & $64.4 \pm 16.6$ & 0.518 \\
\hline Gender - Male/Female & $12 / 11$ & $6 / 7$ & 1.00 \\
\hline \multicolumn{4}{|l|}{ Histological diagnosis } \\
\hline $\begin{array}{l}\text { Undifferentiated } \\
\text { pleomorphic sarcoma }\end{array}$ & $6(26.1)$ & $2(15.4)$ & \\
\hline Myxofibrosarcoma & $10(43.4)$ & $2(15.4)$ & \\
\hline $\begin{array}{l}\text { Dedifferentiated } \\
\text { liposarcoma }\end{array}$ & $2(8.7)$ & $2(15.4)$ & \\
\hline Pleomorphic liposarcoma & $0(0)$ & $1(7.7)$ & \\
\hline Myxoid liposarcoma & $3(13.0)$ & $1(7.7)$ & \\
\hline Synovial sarcoma & $0(0)$ & $2(15.4)$ & \\
\hline $\begin{array}{l}\text { Low grade } \\
\text { fibromyxosarcoma }\end{array}$ & $0(0)$ & $1(7.7)$ & \\
\hline $\begin{array}{l}\text { Extraskeletal myxoid } \\
\text { chondrosarcoma }\end{array}$ & $0(0)$ & $1(7.7)$ & \\
\hline Leiomyosarcoma & $2(8.7)$ & $0(0)$ & \\
\hline Alveolar soft-part sarcoma & $0(0)$ & $1(7.7)$ & \\
\hline Location - Extremity/Axial & $13 / 10$ & $6 / 7$ & 0.802 \\
\hline Size at first consultation $(\mathrm{mm})$ & $69.3 \pm 50.0$ & $99.5 \pm 71.9$ & 0.170 \\
\hline FNCLCC classification & & & 0.930 \\
\hline Grade I/II/III/Unknown & $4 / 5 / 13 / 1$ & $2 / 4 / 7 / 0$ & \\
\hline AJCC stage & & & 0.530 \\
\hline Stages I/II/III/Unknown & $4 / 11 / 7 / 1$ & $2 / 5 / 6 / 0$ & \\
\hline \multicolumn{4}{|l|}{$\begin{array}{l}\text { Adjuvant therapy in the first } \\
\text { perioperative period }\end{array}$} \\
\hline Chemotherapy - Present/None & $0 / 23$ & $2 / 11$ & 0.239 \\
\hline Radiotherapy - Present/None & $2 / 21$ & $2 / 11$ & 0.951 \\
\hline $\begin{array}{l}\text { Surgical margin - Adequate/ } \\
\text { Inadequate }\end{array}$ & $11 / 12$ & $5 / 8$ & 0.848 \\
\hline $\begin{array}{l}\text { Time to local recurrence } \\
\text { (months) }\end{array}$ & $30.1 \pm 22.4$ & $17.5 \pm 14.3$ & 0.077 \\
\hline Size at recurrence $(\mathrm{mm})$ & $52.4 \pm 29.6$ & $49.1 \pm 24.1$ & 0.729 \\
\hline \multicolumn{4}{|l|}{$\begin{array}{l}\text { Adjuvant therapy in the } \\
\text { second perioperative period }\end{array}$} \\
\hline Chemotherapy - Present/None & $2 / 21$ & $0 / 13$ & 0.7364 \\
\hline Radiotherapy - Present/None & $0 / 23$ & $0 / 13$ & - \\
\hline $\begin{array}{l}\text { Local re-recurrence - } \\
\text { Present/None }\end{array}$ & $10 / 13$ & $6 / 7$ & 0.846 \\
\hline Total re-recurrence rate (\%) & 43.5 & 46.2 & \\
\hline $\begin{array}{l}\text { 5-year local re-recurrence } \\
\text { rate }(\%)\end{array}$ & 47.1 & 33.3 & 0.797 \\
\hline Number of local recurrences & $1.6 \pm 1.0$ & $2.1 \pm 1.4$ & 0.256 \\
\hline $\begin{array}{l}\text { Metastasis after recurrent } \\
\text { surgery - Present/None }\end{array}$ & $5 / 18$ & $5 / 8$ & 0.691 \\
\hline $\begin{array}{l}\text { Total follow up period } \\
\text { (months) }\end{array}$ & $59.8 \pm 40.8$ & $53.3 \pm 36.0$ & 0.552 \\
\hline $\begin{array}{l}\text { Follow up period after } \\
\text { re-operation (months) }\end{array}$ & $39.2 \pm 27.9$ & $34.2 \pm 54.5$ & 0.765 \\
\hline Outcome at the last follow-up & & & 0.548 \\
\hline $\begin{array}{l}\text { Alive without disease/ } \\
\text { Alive with disease/Dead }\end{array}$ & $15 / 1 / 7$ & $7 / 4 / 2$ & \\
\hline
\end{tabular}

Values are expressed as the number and proportion of patients or means \pm standard deviations (SD) with ranges. AO: Acridine orange; FNCLCC: French Federation of Cancer Center Sarcoma Group; AJCC: American Joint Committee on Cancer.
Table II. Univariate logistic regression analysis of factors affecting the local "re-recurrence" of patients.

\begin{tabular}{lccc}
\hline Variables & \multicolumn{3}{c}{ Univariate } \\
\cline { 2 - 4 } & OR & $95 \%$ CI & $p$-Value \\
\hline Age & 1.012 & $0.981-1.044$ & 0.452 \\
Gender - Female & 0.318 & $0.113-0.894$ & 0.030 \\
Location - axial & 1.685 & $0.623-4.554$ & 0.304 \\
Size at first consultation & 1.002 & $0.994-1.010$ & 0.640 \\
FNCLCC classification & 0.999 & $0.519-1.923$ & 0.997 \\
AJCC stage & 1.240 & $0.566-2.714$ & 0.591 \\
First surgical margin - Inadequate & 0.790 & $0.285-2.186$ & 0.649 \\
Time to local recurrence & 1.000 & $0.976-1.024$ & 0.972 \\
Size at recurrence & 0.995 & $0.975-1.015$ & 0.617 \\
Second surgery-AO+ & 1.413 & $0.504-3.956$ & 0.511 \\
Marginal excision & & & \\
Metastasis after recurrent surgery & 2.062 & $0.741-5.736$ & 0.166
\end{tabular}

OR: Odds ratio; 95\%CI: 95\% confidence interval; FNCLCC: French Federation of Cancer Center Sarcoma Group; AJCC: American Joint Committee on Cancer; AO: acridine orange.

Marginal excision with AO therapy was performed on patients when the recurrent tumor was contacting major nerves or vessels, bones, and/or major organs without any signs of massive invasion upon pre-surgery imaging evaluation.

This study was approved by the Institutional Review Board for Clinical Research at Akita University (approval number: 221), and informed consent was obtained from all patients.

Data variables and definitions. Information collected from the patients included: age, gender, histological diagnosis of the tumor, anatomical location of the tumor, primary and recurrence tumor sizes, histological grade, stage of the primary tumor, treatments for the primary and recurrence tumors, local re-recurrence, distant relapse, time to the local recurrence, follow-up period, and outcomes. The stage of the primary tumor was determined based on the staging system of the American Joint Committee on Cancer (AJCC), $7^{\text {th }}$ edition (15). Histological grade of the specimens was classified using the French Federation of Cancer Center Sarcoma Group (FNCLCC) classification. This classification is based on the mitotic index, necrotic extension, and histological differentiation of the tumor (16). In the absence of death, the date of the last followup was defined as the end of the follow-up period. The local rerecurrence-free survival (LRRS) was defined as the period from the surgery for the recurrent tumor till the diagnosis of local rerecurrence. Overall survival (OS) was defined as the period from the date of the primary tumor diagnosis to the last follow-up or death. As there were no deaths due to postoperative complications in this study, we defined the deaths from STS as "died of disease" (DOD). Cases were regarded to have a surgical indication if all lesions, including distant metastases, were able to be excised.

Procedures for AO therapy. We conducted AO therapy, including photodynamic surgery (PDS), photodynamic therapy (PDT), and radiodynamic therapy (RDT), according to methods previously reported (2-7). After marginal excision of STS, a $1 \mu \mathrm{g} / \mathrm{ml}$ solution 


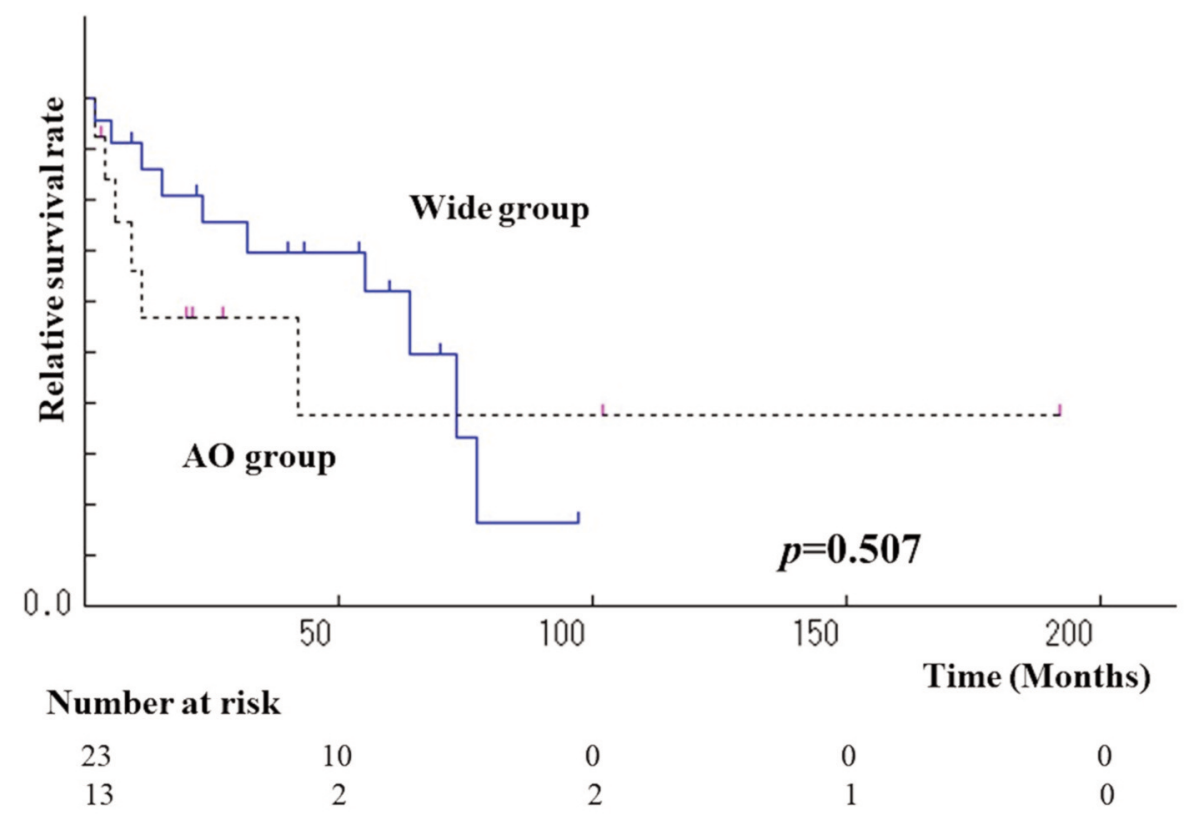

Figure 1. Kaplan-Meier local re-recurrence-free survival curves based on the use of acridine orange in all patients. There was no significant difference between the two groups. AO: Acridine orange.

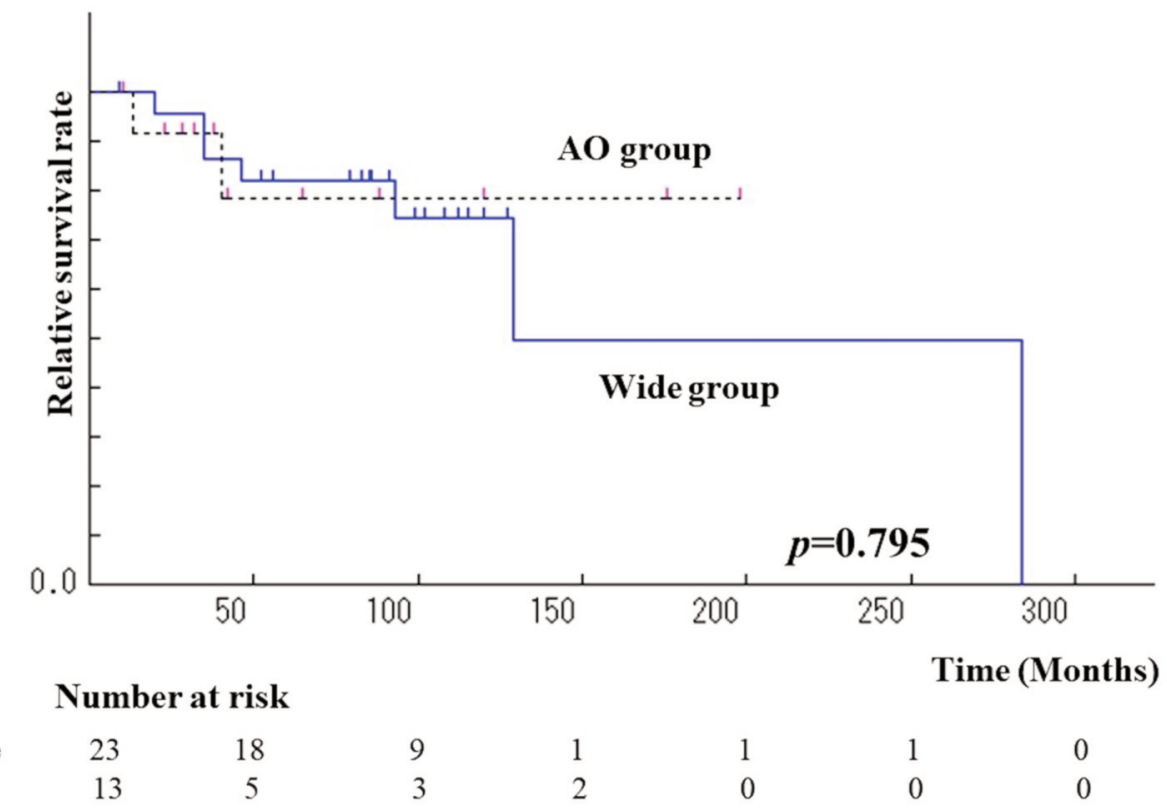

Figure 2. Kaplan-Meier overall survival curves based on the use of acridine orange in all patients. There was no significant difference between the two groups. AO: Acridine orange.

of AO (Sigma Aldrich Co, St Louis, MO, USA) was sprayed around the major nerves, vessels, and organs. Microscopic curettage was conducted using an ultrasonic surgical knife (Olympus Co. Ltd., Tokyo, Japan), a high-power xenon lamp (500 mW; >100,000 lux), and special interference and resorption filters $(450-490 \mathrm{~nm})$ to select only the blue light emitted by a xenon lamp (PDS). Administration of the AO-fluid and microscopic curettage was repeated until the green AO-fluorescence area marking the remaining tumor cells had disappeared completely. PDT was followed by PDS. PDT was subsequently applied to the resected area of the tumor by 
Table III. Univariate and multivariate analysis of factors affecting prognosis.

\begin{tabular}{|c|c|c|c|c|c|c|}
\hline \multirow[t]{2}{*}{ Variables } & \multicolumn{3}{|c|}{ Univariate } & \multicolumn{3}{|c|}{ Multivariate } \\
\hline & OR & $95 \% \mathrm{CI}$ & $p$-Value & OR & $95 \% \mathrm{CI}$ & $p$-Value \\
\hline Age & 1.016 & $0.973-1.060$ & 0.477 & & & \\
\hline Gender - Female & 0.076 & $0.009-0.635$ & 0.017 & 0.165 & $0.019-1.429$ & 0.102 \\
\hline Location - axial & 1.179 & $0.292-4.753$ & 0.817 & & & \\
\hline Size at first consultation & 1.006 & $0.995-1.016$ & 0.282 & & & \\
\hline FNCLCC classification & 2.200 & $0.569-8.515$ & 0.253 & & & \\
\hline AJCC Stage & 3.318 & $0.869-12.662$ & 0.079 & & & \\
\hline Chemotherapy in the first perioperative period & 1.650 & $0.195-13.982$ & 0.646 & & & \\
\hline Radiotherapy in the first perioperative period & 2.193 & $0.437-11.010$ & 0.340 & & & \\
\hline First surgical margin -Inadequate & 0.994 & $0.233-4.249$ & 0.994 & & & \\
\hline Time to local recurrence & 0.978 & $0.942-1.015$ & 0.235 & & & \\
\hline Size at recurrence & 1.032 & $1.010-1.054$ & 0.004 & 1.045 & $1.010-1.081$ & 0.011 \\
\hline Second surgery-AO+Marginal excision & 0.808 & $0.161-4.060$ & 0.796 & & & \\
\hline Local "re-recurrence" & 1.134 & $0.281-4.570$ & 0.860 & & & \\
\hline Number of local recurrences & 1.296 & $0.774-2.170$ & 0.323 & & & \\
\hline Metastasis after recurrent surgery & 7.535 & $1.502-37.797$ & 0.014 & 13.618 & $1.465-126.564$ & 0.022 \\
\hline
\end{tabular}

OR: Odds ratio; 95\%CI: 95\% confidence interval; FNCLCC: French Federation of Cancer Center Sarcoma Group; AJCC: American Joint Committee on Cancer; AO: acridine orange.

illuminating it with $>100,000$ lux of unfiltered light from a xenon lamp for $10 \mathrm{~min}$. The final step, RDT, was performed in patients who agreed to undergo RDT. After closure of the surgical wound, without washing of the AO solution, single-session radiotherapy with 5 Gy was immediately administered to the resected area. Although it was policy to conduct RDT in all cases, we did not conduct RDT when patients did not agree to it or when the radiation room was not available immediately after surgery.

Statistical analysis. We compared the clinical courses and results between the Wide and the AO groups, and analyzed the factors affecting the local re-recurrence and prognosis after the recurrence.

All continuous variables were expressed as means \pm standard deviations (SD). Student's $t$-tests, Welch $t$-tests, and Chi Squared $\left(\chi^{2}\right)$ tests were used to compare characteristics between the two groups. The curves for LRRS and OS were drawn using the Kaplan-Meier method, and differences were analyzed using the generalized Wilcoxon test. A Cox proportional hazards model was used to identify the factors associated with local re-recurrence and prognosis. Probability $(p)$ values less than 0.05 were considered significant.

\section{Results}

The mean follow-up period for all patients was $82.4 \pm 57.8$ months (range $=9-284$ months). The histological diagnoses were myxofibrosarcoma in 12 cases $(33.3 \%)$, undifferentiated pleomorphic sarcoma in 8 cases $(22.2 \%)$, dedifferentiated liposarcoma in 4 cases (11.1\%), myxoid liposarcoma in 4 cases (11.1\%), synovial sarcoma in 2 cases $(5.6 \%)$, leiomyosarcoma in 2 cases $(5.6 \%)$, and 1 case each $(2.8 \%)$ of pleomorphic liposarcoma, low grade fibromyxosarcoma, extraskeletal myxoid chondrosarcoma, and alveolar soft-part sarcoma. The sites of the primary lesions were in the extremities in 19 patients
$(52.8 \%)$ and in axial sites in 17 patients $(47.2 \%)$. The mean tumor size at the primary lesion and recurrence was 81.6 \pm 60.7 $\mathrm{mm}$ (range $=18-250 \mathrm{~mm}$ ) and $51.2 \pm 27.4 \mathrm{~mm}$ (range $=14-130$ $\mathrm{mm}$ ), respectively. The FNCLCC classifications were grade I for 6 patients, grade II for 9 patients, grade III for 20 patients, and unknown for 1 patient. According to the AJCC staging system, the disease stages of the primary tumor were IA for 2 patients, stage IB for 4 patients, stage IIA for 14 patients, stage IIB for 2 patients, stage III for 13 patients, and unknown for 1 patient. Neoadjuvant chemotherapies in the perioperative period, involving doxorubicin and ifosfamide, were administered to 2 patients for the primary tumor and 2 patients for the recurrent lesions. Adjuvant radiotherapy was performed for 4 patients in the primary perioperative period. Adequate tumor-free margins for the primary tumor were achieved for 16 patients $(44.4 \%)$. The mean period until the appearance of local recurrence for all patients was 25.6 \pm 20.6 months (range $=2-68$ months). In the AO group, the combined treatment of PDS and PDT for the recurrent lesion was performed in $11(84.6 \%)$ patients; PDS, PDT, and RDT for the recurrent lesion were performed in $2(15.4 \%)$ patients. A total of 16 patients $(44.4 \%)$ developed local re-recurrence. The number of local recurrences, including the first recurrence within the follow-up period, was $1.8 \pm 1.2$ times (range $=1-5$ times). Ten patients $(27.8 \%$ ) developed metastases after the initial local recurrence surgery. At the end of the study, no evidence of disease was found in 22 patients, 5 patients were classified as alive with disease, and 9 patients died of disease. No patients died because of complications during the perioperative period.

There were no significant differences in clinical information between the Wide group and the AO group (Table I). The 5- 
year local re-recurrence rate was $47.1 \%$ in the Wide group and $33.3 \%$ in the AO group; the total re-recurrence rate was $43.5 \%$ in the Wide group and $46.2 \%$ in the AO group. There were no significant differences in the Kaplan-Meier curves for local rerecurrence survival and overall survival between the two groups (Figures 1 and 2). In the univariate logistic analysis, which investigated factors associated with the local rerecurrence, only male gender was identified as a risk factor for local re-recurrence $(p<0.05)$ (Table II). In univariate analysis, which investigated factors associated with prognosis, male gender, tumor size at the recurrence, and metastasis after the surgery for the recurrence were identified as risk factors for poor prognosis. Multivariate analysis identified the tumor size at recurrence and metastasis after the surgery as risk factors for poor prognosis $(p<0.05)$ (Table III).

\section{Discussion}

Clinical results of marginal excision with $\mathrm{AO}$ have been reported to be equivalent to wide excision (2-8). In our previous research, we reported that local control of STS by marginal excision with AO therapy was significantly better than that of marginal excision without adjuvant therapy (14). Our current study showed that a marginal excision with AO can provide local control equivalent to a wide excision, even in local and aggressive recurrent STS cases. Marginal excision with $\mathrm{AO}$ requires less tissue to be resected than wide excision, and functional preservation can be expected. Due to the suppressive effects on recurrence and preservation of postoperative function, marginal excision with AO therapy is considered to be an effective treatment.

In the present study, the local re-recurrence rate was relatively high; $43.5 \%$ after the extensive resection and $46.2 \%$ after the marginal excision with AO. Previous reports of local re-recurrent rates of STS ranged from $20-47 \%$, and the results of surgical treatment for local recurrence generally tended to be worse than the results of the initial surgical treatment $(1,17-$ 24). Among these reports, Sugiura et al. analyzed re-recurrence in STS cases, and reported a low re-recurrence rate $(20 \%)$. Furthermore, they reported that a resection with a margin of 2 $\mathrm{cm}$ or more has a local control rate of $87.2 \%$ (17); they had also removed all the scar tissue in the resection area of the initial operation. In some of the present cases, we did not perform sufficient excision of the scar tissue after the initial excision. In addition, the Wide group in the present study included cases whose resection margin is not marginal but less than $2 \mathrm{~cm}$. The lack of a stricter definition of the surgical margin may have led to the present high re-recurrence rate. Although our research shows the effectiveness of adjuvant AO therapy, in cases of local recurrence that was difficult to control locally, AO therapy did not show more efficacy than extensive excision.

This study identified male gender as a risk factor for local re-recurrence. Risk factors for local re-recurrence, such as the excision margin, occurrence in the upper limbs, and no adjuvant therapy, have been reported $(1,17,18)$. In our study, there were no cases of adjuvant radiotherapy in the perioperative period of local recurrence, and few patients received chemotherapy. The relatively low local control rate in our cases may have been affected by not administering adjuvant therapy. However, Torres et al. also reported that adjuvant radiotherapy for local recurrence did not show effectiveness (18). Because there are still conflicting opinions, more cases should be examined in the future to clarify the risk factors of re-recurrence.

The risk factors of prognosis in the cases of local recurrence reported in past studies include the size of the locally recurrent tumor, male gender, and the tumor being histologically high grade (1). In our study, the size of locally recurrent tumor was identified as a poor prognostic factor, along with the appearance of distant metastases. This result shows that a careful follow-up after the first operation is imperative in order to identify local recurrences early.

One of the main limitations of this study was the small number of patients. Several factors may have led to biases, such as histological malignancy, size, and location of the tumor; a larger number of patients are needed to sufficiently analyze these factors. Although we initially targeted more patients, by refining our cases to exclude patients with distant metastasis or amputation, the number of cases in this study was reduced.

This study shows that the inhibitory effect of a marginal excision with adjuvant AO therapy on local re-recurrence of local recurrent STS is just as efficacious as a wide excision. The size of the locally recurrent tumor, and distant metastasis after the surgery for the recurrent lesion affect prognosis, which demonstrates the importance of these factors in the careful follow-up of patients after the first operation.

\section{Conflicts of Interest}

This work was supported by the Japan Orthopedics and Traumatology Foundation, Inc. under Grant (number: 390). Tsuchie $\mathrm{H}$. reports receiving funding from a research grant foundation that may be affected by the research reported in the enclosed paper.

\section{Authors' Contributions}

All Authors were involved in the planning and revising for this research; Tsuchie $\mathrm{H}$, Nagasawa $\mathrm{H}$, Emori $\mathrm{M}$, Murahasi $\mathrm{Y}$, Mizushima E, and Shimizu J collected the clinical data; Tsuchie $\mathrm{H}$ analyzed the raw data; Tsuchie $\mathrm{H}$ wrote this manuscript; Miyakoshi N, Okada K, Yamashita Y, and Shimada Y reviewed this manuscript.

\section{References}

1 Eilber FC, Rosen G, Nelson SD, Selch M, Dorey F, Eckardt J and Eilber FR: High-grade extremity soft tissue sarcomas: factors predictive of local recurrence and its effect on morbidity 
and mortality. Ann Surg 237(2): 218-226, 2003. PMID: 12560780. DOI: 10.1097/01.SLA.0000048448.56448.70

2 Kusuzaki K, Murata H, Matsubara T, Miyazaki S, Okamura A, Seto M, Matsumine A, Hosoi H, Sugimoto T and Uchida A: Clinical trial of photodynamic therapy using acridine orange with/without low dose radiation as new limb salvage modality in musculoskeletal sarcomas. Anticancer Res 25(2B): 1225-1235, 2005. PMID: 15865070.

3 Nakamura T, Kusuzaki K, Matsubara T, Matsumine A, Murata $\mathrm{H}$ and Uchida A: A new limb salvage surgery in cases of highgrade soft tissue sarcoma using photodynamic surgery, followed by photo- and radiodynamic therapy with acridine orange. J Surg Oncol 97(6): 523-528, 2008. PMID: 18348188. DOI: 10.1002/ jso. 21025

4 Matsubara T, Kusuzaki K, Matsumine A, Murata H, Satonaka H, Shintani K, Nakamura T, Hosoi H, Iehara T, Sugimoto T and Uchida A: A new therapeutic modality involving acridine orange excitation by photon energy used during reduction surgery for rhabdomyosarcomas. Oncol Rep 21(1): 89-94, 2009. PMID: 19082447.

5 Matsubara T, Kusuzaki K, Matsumine A, Murata H, Nakamura T, Uchida A and Sudo A: Clinical outcomes of minimally invasive surgery using acridine orange for musculoskeletal sarcomas around the forearm, compared with conventional limb salvage surgery after wide resection. J Surg Oncol 102(3): 271275, 2010. PMID: 20740586. DOI: 10.1002/jso.21602

6 Matsubara T, Kusuzaki K, Matsumine A, Nakamura T, and Sudo A: Can a less radical surgery using photodynamic therapy with acridine orange be equal to a wide-margin resection? Clin Orthop Relat Res 471(3): 792-802, 2013. PMID: 23008027. DOI: $10.1007 / \mathrm{s} 11999-012-2616-9$

7 Nakamura T, Kusuzaki K, Matsubara T, Murata H, Hagi T, Asanuma $\mathrm{K}$ and Sudo A: Long-term clinical outcome in patients with high-grade soft tissue sarcoma who were treated with surgical adjuvant therapy using acridine orange after intra-lesional or marginal resection. Photodiagnosis Photodyn Ther 23: 165-170, 2018. PMID: 29885811. DOI: 10.1016/j.pdpdt.2018.06.001

8 Kusuzaki K, Takai T, Yoshimura H, Inoue K, Takai S and Baldini $\mathrm{N}$ : Clinical Trial of Radiotherapy After Intravenous Injection of Acridine Orange for Patients with Cancer. Anticancer Res 38(1): 481-489, 2018. PMID: 29277813. DOI: 10.21873/anticanres.12248

9 Kusuzaki K, Aomori K, Suginoshita T, Minami G, Takeshita H, Murata H, Hashiguchi S, Ashihara T and Hirasawa Y: Total tumor cell elimination with minimum damage to normal tissues in musculoskeletal sarcomas following photodynamic therapy with acridine orange. Oncology 59(2): 174-180, 2000. PMID: 10971178. DOI: 10.1159/000012156

10 Kusuzaki K, Murata H, Takeshita H, Hashiguchi S, Nozaki T, Emoto K, Ashihara T and Hirasawa Y: Intracellular binding sites of acridine orange in living osteosarcoma cells. Anticancer Res 20(2A): 971-975, 2000. PMID: 10810383.

11 Kusuzaki K, Suginoshita T, Minami G, Aomori K, Takeshita H, Murata H, Hashiguchi S, Ashihara T and Hirasawa Y: Fluorovisualization effect of acridine orange on mouse osteosarcoma. Anticancer Res 20(5A): 3019-3024, 2000. PMID: 11062717.

12 Kusuzaki K, Takeshita H, Murata H, Gebhardt MC, Springfield DS, Mankin HJ, Ashihara T and Hirasawa Y: Polyploidization induced by acridine orange in mouse osteosarcoma cells. Anticancer Res 20(2A): 965-970, 2000. PMID: 10810382.
13 Matsubara T, Kusuzaki K, Matsumine A, Shintani K, Satonaka $\mathrm{H}$ and Uchida A: Acridine orange used for photodynamic therapy accumulates in malignant musculoskeletal tumors depending on $\mathrm{pH}$ gradient. Anticancer Res 26(1A): 187-193, 2006. PMID: 16475697.

14 Tsuchie H, Emori M, Miyakoshi N, Nagasawa H, Okada K, Murahashi Y, Mizushima E, Shimizu J, Yamashita T and Shimada Y: Impact of acridine orange in patients with soft tissue sarcoma treated with marginal resection. Anticancer Res 39(11): 6365-6372, 2019. PMID: 31704869. DOI: 10.21873/anticanres.13849

15 Edge SB and Compton CC: AJCC cancer staging handbook. $7^{\text {th }}$ ed, Springer, New York; Springer 2010.

16 Coindre JM, Terrier P, Bui NB, Bonichon F, Collin F, Le Doussal V, Mandard AM, Vilain MO, Jacquemier J, Duplay H, Sastre X, Barlier C, Henry-Amar M, Macé-Lesech J and Contesso G: Prognostic factors in adult patients with locally controlled soft tissue sarcoma. A study of 546 patients from the French Federation of Cancer Centers Sarcoma Group. J Clin Oncol 14(3): 869-877, 1996. PMID: 8622035. DOI: 10.1200/ JCO.1996.14.3.869

17 Sugiura H, Nishida Y, Nakashima H, Yamada Y, Tsukushi S and Yamada K: Surgical procedures and prognostic factors for local recurrence of soft tissue sarcomas. J Orthop 19(1): 141-149, 2014. PMID: 24081391. DOI: 10.1007/s00776-013-0469-z

18 Torres MA, Ballo MT, Butler CE, Feig BW, Cormier JN, Lewis VO, Pollock RE, Pisters PW and Zagars GK: Management of locally recurrent soft-tissue sarcoma after prior surgery and radiation therapy. Int J Radiat Oncol Biol Phys 67(4): 1124-1129, 2007. PMID: 17208389. DOI: 10.1016/j.ijrobp.2006.10.036

19 Ramanathan RC, A'Hern R, Fisher C and Thomas JM: Prognostic index for extremity soft tissue sarcomas with isolated local recurrence. Ann Surg Oncol 8(4): 278-289, 2001. PMID: 11352300. DOI: $10.1007 / \mathrm{s} 10434-001-0278-\mathrm{z}$

20 Trovik CS: Scanadinavian Sarcoma Group Project. Local recurrence of soft tissue sarcoma. A Scandinavian Sarcoma Group Project. Acta Orthop Scand Suppl 72(300): 1-31, 2001. PMID: 11381580 .

21 Pearlstone DB, Janjan NA, Feig BW, Yasko AW, Hunt KK, Pollock RE, Lawyer A, Horton J and Pisters PW: Re-resection with brachytherapy for locally recurrent soft tissue sarcoma arising in a previously radiated field. Cancer J Sci Am 5(1): 2633, 1999. PMID: 10188058

22 Karakousis CP, Proimakis C, Rao U, Velez AF and Driscoll DL: Local recurrence and survival in soft-tissue sarcomas. Ann Surg Oncol 3(3): 255-260, 1996. PMID: 8726180. DOI: 10.1007/ bf02306280

23 Robinson M, Barr L, Fisher C, Fryatt I, Stotter A, Harmer C, Wiltshaw E and Westbury G: Treatment of extremity soft tissue sarcomas with surgery and radiotherapy. Radiother Oncol 18(3): 221-233, 1990. PMID: 2217870. DOI: 10.1016/01678140(90)90058-5

24 Giuliano AE, Eilber FR and Morton DL: The management of locally recurrent soft-tissue sarcoma. Ann Surg 196(1): 87-91, 1982. PMID: 7092358. DOI: 10.1097/00000658-198207000-00018

Received April 13, 2020

Revised April 24, 2020

Accepted April 27, 2020 